\title{
Determining onset of significant facial pathology using dental wear and microwear texture analysis: a case study from the Mid- dle Archaic ( 5,500 BP) of Indiana.
}

Anna Casserly ${ }^{1}$, Rebecca Van Sessen ${ }^{2}$, Christopher Schmidt ${ }^{3}$

${ }_{1}^{1}$ Department of Anthropology, University of Kentucky, Lexington, Kentucky 40506

${ }^{2}$ Department of Sociology and Anthropology, Indiana University- Northwest, Gary, Indiana 46408

${ }^{3}$ Department of Anthropology, University of Indianapolis, Indianapolis, Indiana 46227

Keywords: treponemal disease, paleopathology, macrowear

ABSTRACT Paleopathologists face complicated presentations of osteological conditions that accrued over a considerable period of illhealth. Determining the relative sequence of symptoms and how long the individual lived with them is critical to understanding disease onset and progression in the body and may help to identify a specific disease. This paper describes an atypical presentation of the dentition associated with a 5,000-year-old case of treponemal disease. This

Burial 54 (B. 54) is a young adult female from Meyer site (12Sp1082), a late Middle Archaic mortuary in southern Indiana. She presents considerable evidence of a pathological condition, with the cranio-facial bones being the most impacted (Figure 1). Notably for this study, the anterior maxillary alveolar margin is completely resorbed, resulting in antemortem loss of the anterior dentition from the right lateral incisor to the left first premolar. The mandible indicates major changes to the alveolar region as well; the bone appears to have been weakened to the point of collapsing under the dentition, causing the lower anterior teeth to jut forward at a near $90^{\circ}$ angle to their natural position. In addition, the right body of the mandible was the site of a severe lytic lesion measuring at least $39 \mathrm{~mm}$ in length. The right lower molars were present at recovery, indicating that they were held within the soft-tissue. Together, these conditions were determined to be the result of a treponemal infection (Casserly 2013). All of the teeth show some level of macrowear; caries are absent. The only teeth shed antemortem are those of the anterior maxilla mentioned already. The teeth are morphologically similar to those of other people in the cemetery and there are no obvious defects in dental hard tissue quantity or quality. circumstance led to a cessation of macrowear, which allowed for an estimation of the age when the jaw began to profoundly deform. This paper also summarizes molar microwear texture analysis (DMTA) that was employed in order to determine if the diet of the victim prior to death was consistent with other people from the site.

\section{DENTAL MACROWEAR AND MICROWEAR}

The objective of the macrowear study was to determine when the bones supporting the dentition started to fail and move the teeth out of their normal anatomical orientations. To accomplish this, the dental macrowear was documented and compared to others from the cemetery in order to determine the approximate age of the individual at the time when the incisors no longer came into contact. The molars were similarly analysed to determine if the point of their disuse corresponded to that of the incisors. The dental microwear texture analysis (DMTA) was undertaken to determine the similarity of B. 54 's diet to others from the site in order to determine if she was able to consume typical foods up until the point when she finally succumbed to the disease.

\section{METHODS}

We scored dental macrowear by direct observation following guidelines described by Smith (1984) for the anterior teeth and Scott (1979) for the

\section{Correspondence to:}

Anna Casserly, Dept. of Anthropology, University of Kentucky, 211 Lafferty Hall, 150 Patterson Dr., Lexington, KY, 40506-0027

Email: acasserly@gmail.com

Telephone:(859) 257-2710 
molars. DMTA followed guidelines described by Scott et al. (2006). Molars of seven Meyer individuals, including the lower left M2 from B. 54 were replicated with high resolution polyvinylsiloxane impression material and cast with an epoxy-resin. Areas of Phase II occlusal facets that were approximately $242.38 \times 181.18 \mu \mathrm{m}$ were viewed with a white light confocal profiler (WLCP) at 100X. Analysis of data clouds was conducted via scale sensitive fractal analysis software (Sfrax ${ }^{\circledR}$ and ToothFrax $\left.{ }^{\circledR}\right)$, which calculates a number of topographic variables including surface complexity (roughnesss) and anisotropy (similarity of feature orientations). In general, hunter-gatherers (like the population from which B.54 originated) tend to have rough surfaces and moderate anisotropy due to their poorly processed and diverse diets.

\section{RESULTS}

Burial 54 had anterior tooth wear scores that were in the stage 3 to 4 range. Compared to others in her cemetery, the only people with similar anterior wear were two 12 to 14 year-olds. Her left first molar scored 31 in the Scott's (1979) system and the right first molar scored a 32. Thus, her molars were worn to nearly identical levels on both sides of her mouth. Only left side molars were suitable for DMTA; the right molars had a thin veneer of occlusal calculus that obscured the surface from view. The means texture values for the Meyer site were 1.276 for complexity and 0.002 for anisotropy. The DMTA values for Burial 54 were 0.847 for complexity and 0.002 for anisotropy.

\section{DISCUSSION}

The maxillary condition that B. 54 presents is similar to the handful of other individuals from the Middle Archaic to also have been diagnosed with treponematosis. Snow (1948) describes a young adult male from Indian Knoll (B. 490) with maxillary resorption that is much like that of B. 54. But that burial does not have the anterior tilt to the mandibular dentition and there is no discussion of a mandibular lytic lesion. In fact, of the four or five possible to likely cases of treponemal disease at Indian Knoll, none have the mandibular involvement seen in B. 54. It may be that B. 54 has a unique manifestation of treponematosis, or it may be that she actually has more than one condition and that either the lytic lesion, the anterior tilt of the mandibular teeth, or both are related to separate maladies.

Burial 54's macrowear scores indicate that she began to lose normal maxillary and mandibular incisal contact in her adolescence perhaps around the time she entered puberty. Thus, the condition, or conditions, she had were chronic and she endured them for what was probably a decade or more. Her molar macrowear indicates that she maintained a typical diet for most of her life, although the occlusal calculus on the right side molars indicates that those teeth were no longer being used at the end of her life.
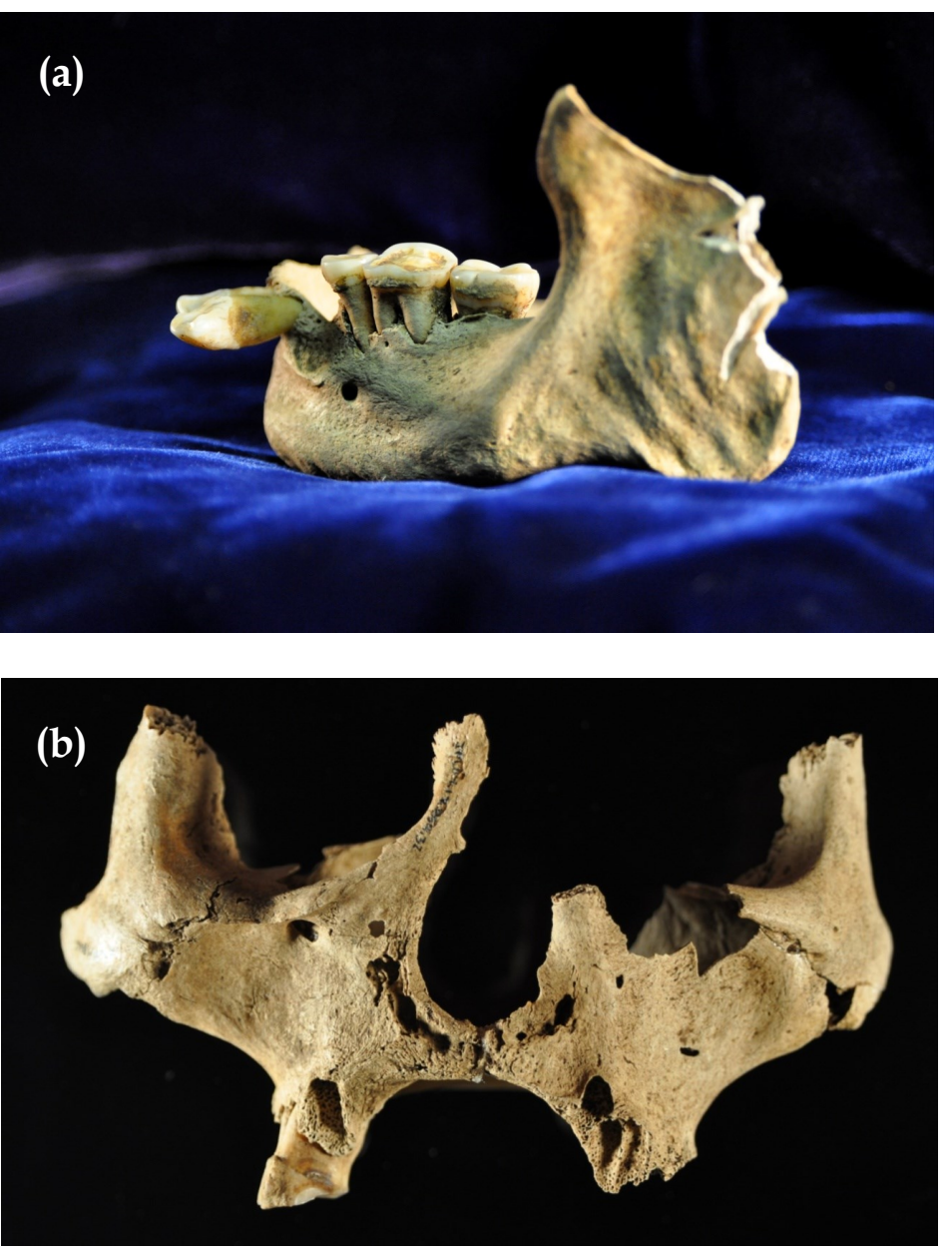

Fig. 1. (a) Left view of mandible showing impact on anterior dentition (b) Facial destruction of Burial 54. Note the maxillary resorption, nasal aperture reduction, and antemortem fracture of left frontal process of maxilla.

TABLE 1. Dental microwear texture analysis scores for Meyer

\begin{tabular}{lll}
\multicolumn{3}{c}{ site } \\
\hline Individual & Complexity & Anisotropy \\
\hline Burial 54 & .8477 & .0016
\end{tabular}

Surface Mand. A $\quad 1.4071 \quad .0036$

$\begin{array}{lll}\text { Burial } 42 & .6905 & .0007\end{array}$

$\begin{array}{lll}\text { Burial } 46 & .9854 & .0023\end{array}$

$\begin{array}{lll}\text { Burial } 104 \quad 2.4398 & .0037\end{array}$

$\begin{array}{lll}\text { Burial } 109 & 1.14156 \quad .0009\end{array}$

$\begin{array}{lll}\text { Burial } 111 & .9912 & .0079\end{array}$

2014 | Volume 27 | Issues 01 and 02 
In fact the right side molar enamel is pitted microscopically (which is visible in areas that were not covered with calculus). It is possible the pitting is the result of an acidic oral environment, which may be the result of abnormal saliva secretion or pus, which can have a $\mathrm{pH}$ around 6 (Nekoofor et al., 2009). Microscopic pitting was not found on the leftside molars.

As a whole, the Meyer site has a DMTA complexity value that is very low for a foraging population indicating that the Meyer diet likely had a high meat component. Burial 54's microwear values are low even for the Meyer Site, but they are not the lowest in the population; that distinction is held by a 12-year-old boy who was killed and decapitated. Dental texture reflects the last few weeks of one's life, so it appears that her diet was comparable to other people in her population even if only her left side dentition was in use. It is possible that softer foods became more dominant toward the end, but in general her microwear does not indicate a wholesale change her diet at any point before she died. Figure 2 shows a bivariate scatterplot of complexity and anisotropy for the Meyer sample.

\section{CONCLUSION}

This study demonstrates the value of dental anthropology in general and macrowear and microwear in particular to help reconstruct the circumstances of a particularly devastating disease condition. The dental data informed us on the age of onset for certain manifestations of the condition as well as the impact the condition had on the victim's diet. Moreover, it aided in the determination of the duration of the condition, which is important for those attempting to better understand the progression of diseases like treponematosis among ancient people. It is hoped that others will consider microwear and macrowear as tools to assist with their diagnoses and analyses in paleopathology.

\section{LITERATURE CITED}

Casserly AC. 2013. Infectious Disease at the Meyer Site. MS Thesis. University of Indianapolis, Indianapolis, IN.

Bader AT. 2010. Evidence of ritualized mortuary behavior at the Meyer Site: an inadvertent discovery in Spencer County, Indiana. Indiana Archaeology. 5:10-49.

Frazer L. 2011. Dental microwear texture analysis of Early/Middle Woodland and Mississippian populations from Indiana. MS Thesis. University of Indianapolis, Indianapolis, IN.

Krueger KL, Scott, JR, Kay, RF, Ungar, PS. 2008. Technical note: dental microwear textures of "Phase I" and "Phase II" facets. Am J Phys Anthropol 137:485-490.

Maier W, Schneck, G. 1982. Functional morphology of hominoid dentitions. J Hum Evol 11:693-696.

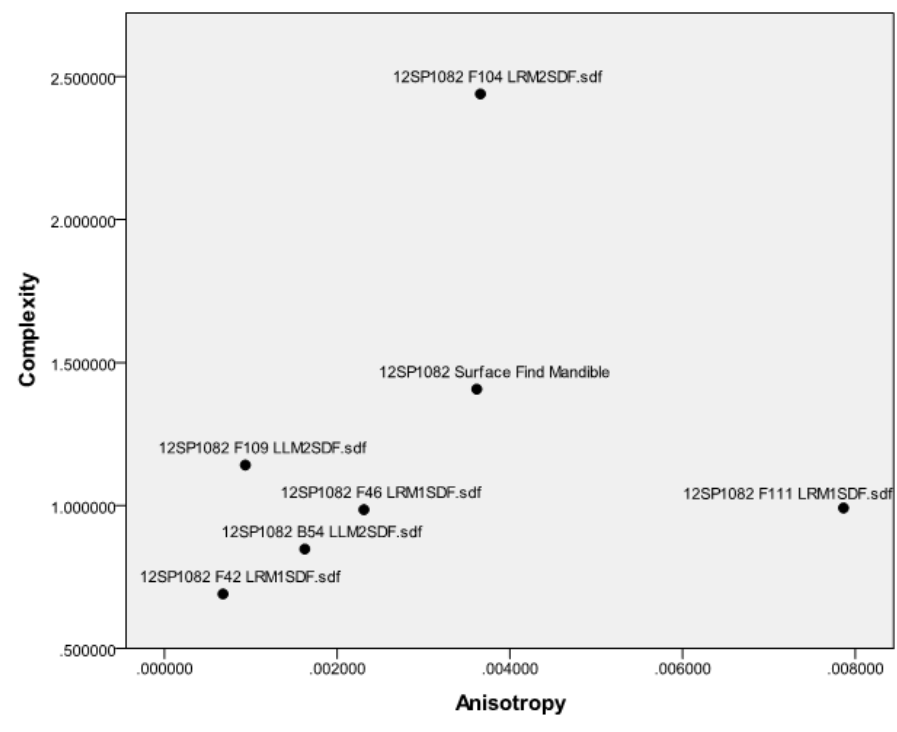

Fig. 2. Bivariate scatterplot of complexity and anisotropy.

Nekoofar MH, Namazikhah MS, Sheykhresae MS, Mohammadi MM, Kazemi A, Aseeley Z, Dummer PM. 2009. $\mathrm{pH}$ of pus collected from periapical abscesses. Int Endod J. 42:534-538.

Schmidt CW, Lockhart RA, Newman C, Serrano A, Zolnierz M, Bader AT, Plunkett JA. 2010. Skeletal evidence of cultural variation: mutilation related to warfare and mortuary treatment. In: Auerbach BM, ed. Human Variation in the Americas: the Integration of Archaeology and Biological Anthropology, Occasional Paper No. 38. Carbondale IL: Center for Archaeological Investigations, pp. 215-237.

Schmidt CW, Chiu LW, Frazer L, Barrett C, Mahoney P. 2011. Dental microwear texture analysis of Natufian Hunter-Gatherers and Neolithic farmers from Northern Israel. Am J Phys Anthropol Suppl 51: 265.

Scott EC. 1979. Dental wear scoring technique. Am J Pys Anthropol 51:213-218.

Scott RS, Ungar, PS, Bergstrom TS, Brown CA, Childs BE, Teaford, MF, Walker A. 2006. Dental microwear texture analysis: technical considerations. J Hum Evol 51: 339-349.

Smith BH. 1984. Patterns of molar wear in hunterGatherers and agriculturalists. Am J Phys Anthropol 63:39-56.

Snow CE, Webb WS, Haag WG. 1948. Indian Knoll skeletons of Site Oh 2, Ohio County, Kentucky. University of Kentucky, Dept. of Anthropology.

Teaford MF, Lytle JD. 1996. Brief communication: dietinduced changes in rates of human tooth microwear: a case study involving stone-ground maize. Am J Phys Anthropol 100:143-147. 